\title{
RETRACTED ARTICLE: Inhibitory effect of discoidin domain receptor 2 (DDR2) on oxygen-induced retinopathy in mice
}

\author{
Rong Li • Tian Huang • Tong Zhu
}

Received: 24 April 2014 /Revised: 16 July 2014 / Accepted: 29 August 2014 / Published online: 10 September 2014

(C) Springer-Verlag Berlin Heidelberg 2014

This article, "Inhibitory effect of discoidin domain receptor 2 (DDR2) on oxygen-induced retinopathy in mice", published OnlineFirst in Graefe's Archive for Clinical and Experimental Ophthalmology, DOI 10.1007/s00417-014-2798-9, has been retracted at the request of the Editor-in-Chief. The data in this article was used without acknowledgement or approval by the research team. The online version of this article contains the full text of the retracted article as electronic supplementary material.

The online version of this article (doi:10.1007/s00417-014-2798-9)

contains supplementary material, which is available to authorized users.

R. Li $(\bowtie)$

Department of Ophthalmology, The Affiliated Hospital,

Xi'an Medical University, No.48 West Fenghao Road,

Xi'an 710077, Shaanxi, China

e-mail: rechelrong198222@163.com

T. Huang

Department of Children's Health Prevention, Xi' an No.4 Hospital,

No.21 Jiefang Road, Xi'an 710004, Shaanxi, China

T. Zhu

Department of Ophthalmology, Xijing Hospital, Fourth Military

Medical University, No.169 West Changle Road,

Xi'an 710032, Shaanxi, China 